\title{
Preparation of Refractory Calcium Aluminate Cement using the Sonochemical Process
}

\author{
Rafaela Roberta Lourenço ${ }^{\mathrm{a}}$, Rômulo Simões Angélica ${ }^{\mathrm{b}}$,José de Anchieta Rodrigues ${ }^{\mathrm{a} *}$ \\ ${ }^{a}$ Materials Microstructure Engineering Group, Department of Materials Engineering, \\ Federal University of São Carlos - UFSCar, São Carlos, SP, Brazil \\ 'Institute of Geosciences, Federal University of Pará - UFPA, Belém, PA, Brazil
}

Received: August 13, 2012; Revised: November 28, 2012

\begin{abstract}
Calcium aluminate cements (CAC) were prepared using the sonochemical process, followed by heat treatment. A study was made of the action of ultrasonic waves and the influence of thermal treatment conditions on two initial molar compositions of 1:1 and 1:2 of calcia:alumina. The aqueous suspension containing the raw materials ( $\mathrm{A}-50$ alumina and $\mathrm{CaO}$ ) was subjected to an ultrasonic bath, followed by drying and burning at 1000,1200 and $1300^{\circ} \mathrm{C}$. These cements were characterized by SEM, XRD and the mechanical strength was evaluated by splitting tensile tests, using commercial cement as a reference. Furthermore, the phases were semi-quantified using the Rietveld method. The results show that hydration and sonochemical action increased the reactivity of the raw materials during firing and that phase formation is dependent on the thermal treatment conditions. The CAC cements were obtained at temperatures at least $200{ }^{\circ} \mathrm{C}$ lower than those used in conventional methods, indicating the potential of this route of synthesis.
\end{abstract}

Keywords: sonochemistry, heat treatment, synthesis, calcium aluminate cement

\section{Introduction}

Calcium aluminates are used as binders in refractory castables because these compounds present high refractoriness, good performance in corrosive environments and phases with excellent hydration capacity. Moreover, when in contact with water, these phases form hydrates whose structures can give the material considerable mechanical strength at room temperature ${ }^{1-3}$.

Aluminous cements are prepared by melting or sintering processes in special furnaces. Raw materials, which have specific mineralogical compositions, are crushed or milled to reduce them to fine and homogeneous powder, facilitating the chemical reactions that occur in the burning process. At this stage, the chemical and mineralogical compositions of the raw materials undergo major changes, giving rise to a product with new characteristics known as clinker ${ }^{1,4,5}$.

Electrofusion is used by some cement manufacturers in countries where electricity is relatively cheap. However, sintering raw materials in rotary furnaces has proved to be the most feasible means to produce cements with various levels of purity, known as high, intermediate or low alumina cements. The main disadvantages of these types of synthesis are the high temperatures and energy consumption ${ }^{1,5}$.

The products resulting from these preparation methods do not consist of a single phase, but usually different ones from the calcia-alumina system in a variety of contents, plus remaining $\mathrm{CaO}$ and $\mathrm{Al}_{2} \mathrm{O}_{3}$ that did not react during the process. They may also contain some undesirable phase formed due to the impurities of the raw materials. The most important constituents of calcium aluminate cements,

*e-mail: josear@ufscar.br
$\mathrm{CAC}$, in decreasing order of concentration are calcium monoaluminate, $\mathrm{CaAl}_{2} \mathrm{O}_{4}(\mathrm{CA})$, calcium dialuminate, $\mathrm{CaAl}_{4} \mathrm{O}_{7}\left(\mathrm{CA}_{2}\right)$ and mayenite, $\mathrm{Ca}_{12} \mathrm{Al}_{14} \mathrm{O}_{33}\left(\mathrm{C}_{12} \mathrm{~A}_{7}\right)^{1-3,6}$.

The CA phase is the most important component of aluminous cements. In addition to developing higher mechanical strength in the short period of time available to hydrate a refractory concrete, this phase has a relatively high melting point, i.e., approximately $1600{ }^{\circ} \mathrm{C}$. Although the $\mathrm{CA}_{2}$ phase decomposes at a higher temperature $\left(1750^{\circ} \mathrm{C}\right)$, it cannot act as the main component of CAC because of its very long hardening time and the low mechanical strength it generates. However, the presence of CA may hasten the set time of the $\mathrm{CA}_{2}$ phase, which is why it appears in aluminous cements as a secondary phase. On the other hand, the $\mathrm{C}_{12} \mathrm{~A}_{7}$ phase has a relatively low melting temperature $\left(\sim 1430^{\circ} \mathrm{C}\right)$, but hydrates and hardens rapidly. This component can therefore be used to control the hardening rate of commercial cements ${ }^{1,4,6,7}$.

In the sintering process, calcium aluminates are formed by a solid state reaction, which is triggered by a chemical diffusion mechanism that occurs among the reagents. This diffusive transport is facilitated by the increase in the interfacial contact area between the solid particles and temperature. In the conventional preparation route, a CaO-rich phase is formed initially. With an increasing temperature or over time, this phase reacts with the available $\mathrm{Al}_{2} \mathrm{O}_{3}$, forming a desired phase. For example, to prepare the $\mathrm{CA}$ phase, calcium oxide and alumina are mixed in molar proportions of $1: 1$ and heated between 1200 and $1400{ }^{\circ} \mathrm{C}$. All the other thermodynamically stable phases with higher 
calcium oxide contents are formed initially. As the reaction time progresses or the temperature increases, these phases are converted into the target phase, which in this case is the calcium aluminate, $\mathrm{CA}^{8,9}$.

Alternative methods of synthesis have become an increasing target of research aimed at preparing calcium aluminates at lower temperatures than those used in conventional processes. In the process known as the sonochemical method, the reagents, which are initially in suspension, are exposed to ultrasonic waves. When a chemical system is subjected to this type of wave, the material can undergo significant chemical and physical changes, thus rendering the chemical process of interest feasible. Among other beneficial effects, the ultrasonic treatment of liquid-solid systems is able to induce changes in the surface morphology, composition and reactivity of particulate materials. Ultrasonic treatment is therefore expected to induce morphological changes on the surface of both alumina and calcia, making them more reactive and resulting in calcium aluminates produced at lower temperatures than those used in conventional routes ${ }^{10-12}$.

Based on the above, calcium aluminate cements were prepared by the sonochemical process followed by heat treatment using two molar compositions of $1: 1$ and 1:2 of calcia and alumina.

\section{Experimental Procedures}

The calcium aluminates were synthesized using calcium oxide (calcia) supplied by Vetec, and an alumina whose composition contains a considerable content of aluminum hydroxide, A50-alumina, produced by Alcoa Aluminum S. A. in Poços de Caldas-MG, Brazil.

To evaluate the performance of the synthesized calcium aluminates, commercial calcium aluminate cement called
Secar 71, supplied by Lafarge, was used as a reference. According to the manufacturer, this cement consists of $\mathrm{CA}, \mathrm{CA}_{2}$ and $\mathrm{C}_{12} \mathrm{~A}_{7}$ phases with contents of $61,37.5$ and 1.5 wt. (\%), respectively. Pastes, made of cement and alumina, were prepared for the splitting tensile tests. The calcined alumina used for this purpose was A1000 SG (Almatis).

The chemical composition and other characteristics of those raw materials are listed in Table 1 . In this paper, we use the symbol wt. (\%) to indicate weight percentage.

Concerning A50-alumina (Table 1), it was observed that there was a loss of $9.76 \mathrm{wt} .(\%)$ due to the moisture and hydrates in this raw material. However, result of the thermogravimetric analysis (TGA) indicates that the content of residues and impurities lost up to $1448{ }^{\circ} \mathrm{C}$ was approximately $17 \mathrm{wt}$. (\%). The correction factor of 1.203 was subtracted from these data to calculate the mass of alumina in the formulation of the cements ${ }^{13}$.

The calcium oxide was first heat treated at $1000{ }^{\circ} \mathrm{C}$ for 1 hour to avoid the presence of any hydroxide, while the alumina was not pretreated. Calcia and alumina were mixed stoichiometrically according to the calcium aluminate phase desired predominantly, i.e., in molar proportions of 1:1 calcia:alumina for the CA phase and 1:2 for the $\mathrm{CA}_{2}$ phase.

An aqueous suspension was prepared by handmixing the calcia and A50 powders with distilled water. The water/solid ratio used was 30/1. This suspension was subjected to an ultrasonic bath (Ultrasonic Cleaner Thornton, $25 \mathrm{kHz}, 1800 \mathrm{~W}$ ) for 1 hour at room temperature $\left(25^{\circ} \mathrm{C}\right)$. The suspension was shaken periodically during the process to enhance the sonochemical effect ${ }^{12}$. Finally, the suspension was oven-dried at $110{ }^{\circ} \mathrm{C}$ for 24 hours. The resulting solid material was ground and then heat-treated.

To evaluate the action of the ultrasonic waves in this system after the sonochemical process, samples of each composition, $\mathrm{CA}$ and $\mathrm{CA}_{2}$, were heat-treated at $1000{ }^{\circ} \mathrm{C}$

Table 1. Chemical composition and physical characteristics of the following raw materials: A50-alumina, CaO, Secar 71 and A1000 SG.

\begin{tabular}{|c|c|c|c|c|}
\hline \multirow{2}{*}{$\frac{\text { Parameters }}{\text { Components (wt. (\%)) }}$} & \multicolumn{4}{|c|}{ Raw materials } \\
\hline & A50-alumina & $\mathrm{CaO}$ & Secar 71 & A1000 SG \\
\hline $\mathrm{Al}_{2} \mathrm{O}_{3}$ & 90.293 & --o- & 68 & 99.8 \\
\hline $\mathrm{CaO}$ & 0.079 & Min. 95 & 31 & 0.02 \\
\hline $\mathrm{Na}_{2} \mathrm{O}$ & 1.260 & $-\cdots$ & 0.5 & 0.07 \\
\hline $\mathrm{SiO}_{2}$ & 0.096 & $-{ }^{----}$ & 0.8 & 0.03 \\
\hline $\mathrm{Fe}_{2} \mathrm{O}_{3}$ & 0.031 & $\cdots$ & $-\cdots--$ & $\cdots$ \\
\hline $\mathrm{MnO}$ & 0.0007 & $\cdots$ & $-\cdots$ & $\cdots$ \\
\hline Sulfate $\left(\mathrm{SO}_{4}\right)$ & $-\cdots$ & Max. 0.5 & ---- & 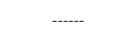 \\
\hline Iron $(\mathrm{Fe})$ & -.--- & Max. 0.1 & $-\cdots+-$ & $-\cdots$ \\
\hline Chloride $(\mathrm{Cl})$ & $-\cdots-$ & Max. 0.05 & --o-- & -.-- \\
\hline Heavy metals (e.g., Pb) & $\cdots$ & Max. 0.005 & $\cdots$ & $-\cdots+-$ \\
\hline LOI & 5.03 & Max. 3 & $-\cdots-$ & $\ldots-$ \\
\hline U110 & 1.52 & ---- & ---- & -..-- \\
\hline U300 & 3.21 & 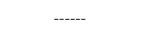 & --.-- & $-\cdots+-$ \\
\hline Density $\left(\mathrm{g} . \mathrm{cm}^{-3}\right)$ & $-\cdots$ & $-\cdots$ & 2.98 & 3.95 \\
\hline Surface Area $\left(\mathrm{m}^{2} \cdot \mathrm{g}^{-1}\right)$ & $-\cdots$ & $-{ }_{-1}$ & 1.17 & 8.4 \\
\hline $\mathrm{D}_{50}(\mu \mathrm{m})$ & 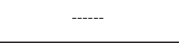 & 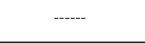 & 13 & 0.57 \\
\hline
\end{tabular}


for 1 hour, together with samples of both compositions that were not exposed to ultrasound. In the latter case, the calcia and alumina were weighed in the proper molar proportions, placed in a mortar, and mixed by hand with a pestle to homogenize the powders prior to the heat treatment.

To establish the influence of the heat treatment temperature and time in the synthesis of the cements, samples of each composition, $\mathrm{CA}$ and $\mathrm{CA}_{2}$, were subjected to temperatures of 1000,1200 and $1300^{\circ} \mathrm{C}$, with a duration of 1 and 6 hours at each of these temperatures.

The calcium aluminate phases in the heat-treated samples were identified based on their X-ray diffraction patterns (XRD). The powder was analyzed in a Rigaku Rotaflex RU-200B diffractometer, using $\mathrm{Cu} \mathrm{K} \alpha$ radiation, a nickel filter, and a $2 \theta$ scanning angle varying from $10^{\circ}$ to $70^{\circ}$. Semi-quantitative analyses were performed in the X-Ray Laboratory of the Institute of Geosciences at the Federal University of Pará. In this laboratory, the analyses were carried out with a PANalytical X'PERT PRO MPD (PW3040/60) X-ray diffractometer, also with $\mathrm{Cu} \mathrm{K \alpha}$ radiation and nickel filter, and a scanning interval of $2 \theta$ from $5^{\circ}$ to $80^{\circ}$. The detector used was a Real Time Multiple Strip (RTMS) $\mathrm{X}^{\prime}$ Celerator, which is a new technology in terms of solid-state linear detectors, with 128 channels. Because this device has no receiving sleet, each channel acts as a receiving sleet. The device therefore has 128 parallel detectors, allowing for much faster data acquisition than in devices with conventional detectors. The main advantage is that it provides high counts, which is fundamental for Rietveld refinement. There is a divergent sleet of $0.5^{\circ}$ in the incident beam, followed by an antiscatter sleet with twice that opening size.

A scanning electron microscope, Zeiss DSM960 SEM, was used to obtain morphological information by photomicrographs of the raw materials, the materials obtained from the sonochemical process, and the heattreated materials. The condition of the operation was $20 \mathrm{kV}$ in secondary electron mode and the powder samples were gold-coated using a Balzers SCD50 sputter coater.

To evaluate the mechanical performance of the synthesized products, splitting tensile tests were performed, which allow inferences to be made about the cohesion of the materials, as the predominant stresses in this test are tensile. Cylindrical $2 \mathrm{~cm} \times 2 \mathrm{~cm}$ test specimens were prepared by mixing 50 wt. (\%) of calcined alumina A1000 SG with $50 \mathrm{wt} .(\%)$ of the synthesized material and distilled water in a water/cement ratio of 0.8 . The test specimens were molded in PVC molds and cured in a chamber with $100 \%$ relative humidity at $50{ }^{\circ} \mathrm{C}$ for 72 hours. The specimens were then unmolded and oven-dried at $50{ }^{\circ} \mathrm{C}$ for another 72 hours. After drying, the test specimens were kept in desiccators until the moment the mechanical tests were performed.

The splitting tensile strength was determined using a universal servo-hydraulic testing machine (MTS 810) with a TestStar IIs control system, according to the ASTM C496-90 standard (Splitting Tensile Strength of Cylindrical Concrete Specimens). A load cell of $50 \mathrm{kN}$ was used. Five test specimens of each type of sample were tested. Test specimens were also prepared using commercial refractory cement, Secar 71 as a reference.

\section{Results and Discussion}

\subsection{Chemical composition of the synthesized calcium aluminate cements}

Figure 1 shows two diffractograms of the samples with initial compositions corresponding to the $\mathrm{CA}$ and $\mathrm{CA}_{2}$ phases, subjected to the sonochemical process, oven-dried at $110{ }^{\circ} \mathrm{C}$ and not heat-treated. The main constituents of these samples were alumina $\left(\mathrm{Al}_{2} \mathrm{O}_{3}\right)$, aluminum hydroxide $\left(\mathrm{Al}(\mathrm{OH})_{3}\right)$ and a calcium and aluminum hydrate, $\mathrm{C}_{3} \mathrm{AH}_{6}$ $\left(3 \mathrm{CaO} \cdot \mathrm{Al}_{2} \mathrm{O}_{3} \cdot 6 \mathrm{H}_{2} \mathrm{O}\right)$. For the sample of $\mathrm{CA}$ phase composition, the lines of the greatest intensities belong to $\mathrm{C}_{3} \mathrm{AH}_{6}$. The formation of this hydrate was not favored in the sample with $\mathrm{CA}_{2}$ composition. Surprisingly, the $\mathrm{CaO}$ signal is no longer visible, indicating that its presence was reduced to low levels (<3-5 wt. (\%)) or even that it was completely consumed in the formation of tricalcium aluminate hydrate, which appears in a high concentration.

The calcium oxide, alumina and samples subjected to ultrasound but not heat treated were examined by SEM to compare their morphological characteristics. Figure 2 shows the photomicrographs of these materials.

Note that the two samples subjected to ultrasound show very different morphologies from those of the initial calcia and alumina. The A50-alumina agglomerates vary significantly in size and shape, whereas the $\mathrm{CaO}$ agglomerates are larger, rounded and profusely cracked. After the sonochemical treatment, the particles clearly showed a significant reduction in size. The morphological changes that took place in these samples are related to $\mathrm{C}_{3} \mathrm{AH}_{6}$ compounds formed by the action of the ultrasound and the presence of water. Therefore, ultrasonic waves strongly refine the particle's size and also seem to favor the formation of the hydrated compound. Figure $2 \mathrm{~d}$ clearly shows an original particle fractured by the action of ultrasonic waves.

Two samples of each initial composition corresponding to the $\mathrm{CA}$ and $\mathrm{CA}_{2}$ phases were prepared. After the heat treatment, the coloring of all the samples was found to change from gray to white.

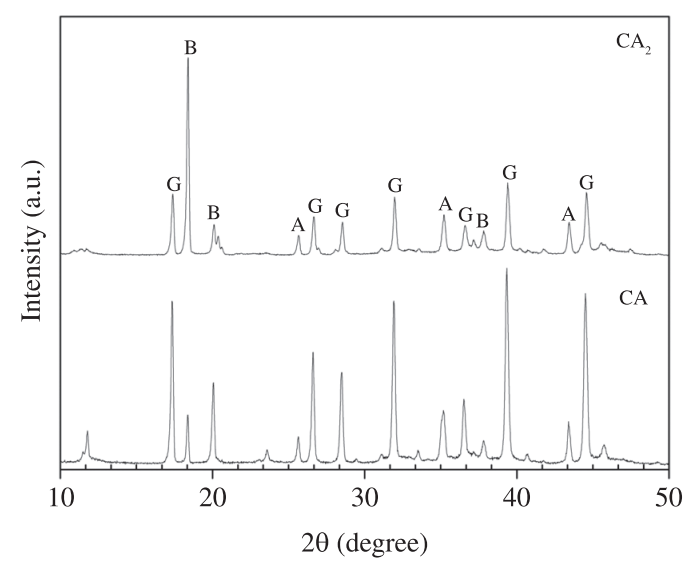

Figure 1. XRD-patterns of the samples with initial compositions correponding to $\mathrm{CA}$ and $\mathrm{CA}_{2}$ phases, which were treated sonochemically, dried at $110{ }^{\circ} \mathrm{C}$, but not heat-treated. Symbols: $\mathrm{A}-\mathrm{Al}_{2} \mathrm{O}_{3} ; \mathrm{B}-\mathrm{Al}(\mathrm{OH})_{3} ; \mathrm{G}-\mathrm{C}_{3} \mathrm{AH}_{6}$. 


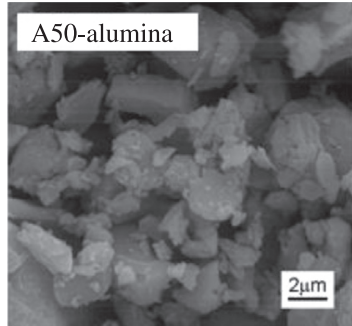

(a)

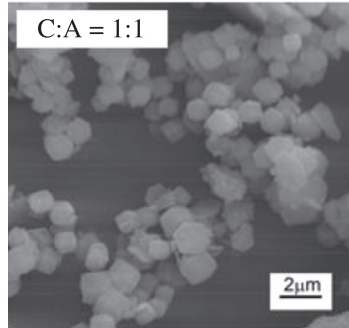

(c)

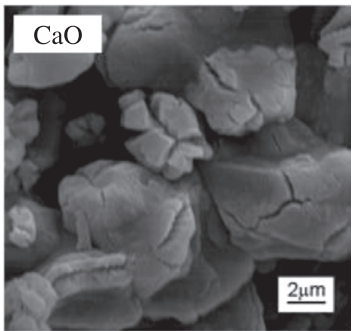

(b)

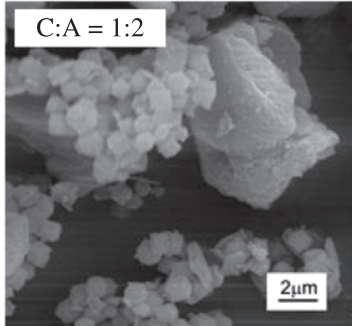

(d)
Figure 2. SEM micrographs: (a) A50-alumina; (b) calcia; (c) and (d), samples with initial molar compositions of 1:1 and 1:2 calcia:alumina, respectively. The materials in images (c) and (d) were treated sonochemically, dried at $110^{\circ} \mathrm{C}$, but not heat-treated.

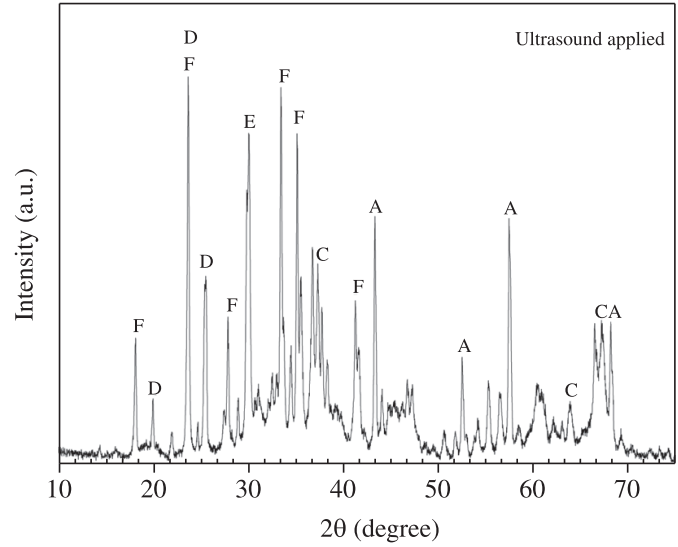

(a)
Figure 3 shows the X-ray diffractograms of the samples with a molar proportion of 1:1 calcia:alumina. Diffractograms (a) and (b) represent, respectively, the sample subjected to the ultrasonic bath and the sample not exposed to ultrasonic waves.

A comparison of the diffractograms of the samples exposed and not exposed to ultrasonic waves reveals a strong change in the diffraction lines. In Figure $3 \mathrm{a}$, the lines with the highest intensity characterize the $\mathrm{C}_{12} \mathrm{~A}_{7}$ phase. For the sample not sonochemically treated, Figure $3 \mathrm{~b}$, the line with the highest intensity corresponds to calcia, one of the starting reagents. Both samples also show lines with lower intensities characteristic of $\mathrm{Al}_{2} \mathrm{O}_{3}$ and of the other phases of the calciaalumina system, $\mathrm{CA}$ and $\mathrm{CA}_{2}$. This comparison indicates that even with a 1 -hour heat treatment at only $1000{ }^{\circ} \mathrm{C}$, the action of the ultrasound was fundamental in triggering the reaction between the raw materials. In Figure 3 a, note how clearly the lines of the target product, CA, appear.

Figure 4 presents diffractograms of the samples with an initial proportion of 1:2 calcia:alumina. In the sample subjected to ultrasonic waves, Figure $4 a$, note that the peaks with the highest intensity characterize the phases of

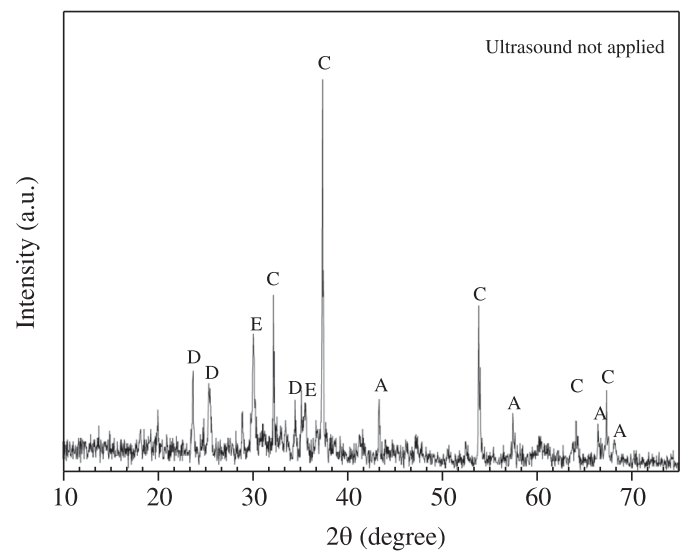

(b)

Figure 3. XRD-patterns of the samples with molar composition of 1:1 calcia:alumina: (a) subjected to ultrasound, and (b) not subjected to ultrasound. Both samples were heat-treated at $100{ }^{\circ} \mathrm{C}$ for 1 hour. Symbols: $\mathrm{A}-\mathrm{Al}_{2} \mathrm{O}_{3} ; \mathrm{C}-\mathrm{CaO} ; \mathrm{D}-\mathrm{CA} ; \mathrm{E}-\mathrm{CA} ; \mathrm{F}-\mathrm{C}_{12} \mathrm{~A}_{7}$

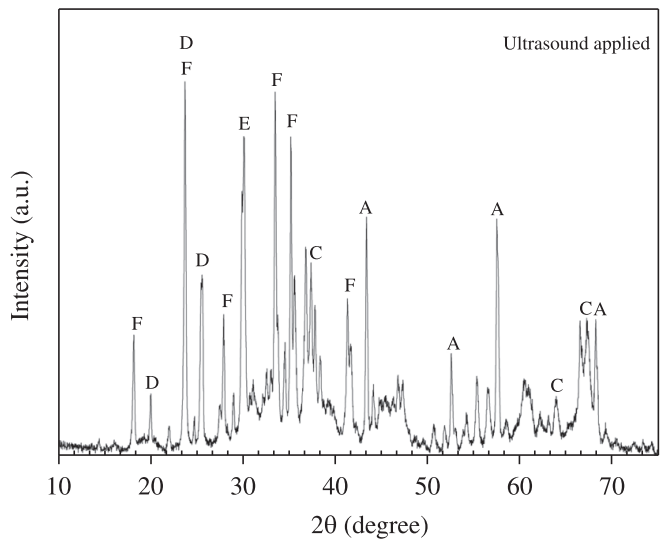

(a)

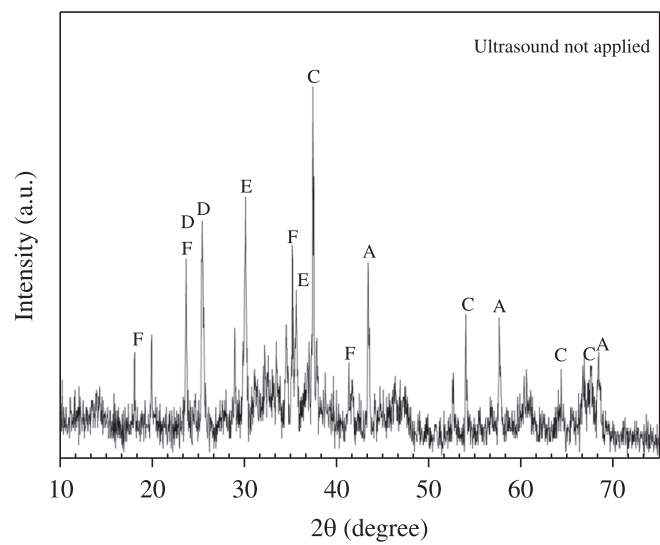

(b)

Figure 4. XRD-patterns of the samples with initial molar composition of 1:2 calcia:alumina: (a) subjected to ultrasound, and (b) not subjected to ultrasound. Both samples were heat-treated at $100{ }^{\circ} \mathrm{C}$ for 1 hour. Symbols: $\mathrm{A}-\mathrm{Al}_{2} \mathrm{O}_{3} ; \mathrm{C}-\mathrm{CaO} ; \mathrm{D}-\mathrm{CA} ; \mathrm{E}-\mathrm{CA} ; \mathrm{F}-\mathrm{C}_{12} \mathrm{~A}_{7}$. 
the calcia-alumina system $\mathrm{CA}_{2}, \mathrm{CA}$ and $\mathrm{C}_{12} \mathrm{~A}_{7}$, while in the sample not treated sonochemically, Figure $4 \mathrm{~b}$, the peak of the highest intensity again corresponds to calcia.

A comparison of the diffractograms (b) in Figures 3 and 4 indicates that in the sample with an initial molar composition of 1:2 calcia:alumina, the characteristic lines of the phases of the binary calcia-alumina system appear with more significant intensities than in the sample with the initial composition of $1: 1$.

Albeit not quantitative, the diffractograms in Figures 3 and 4 indicate that the initial calcia in the samples exposed to ultrasonic waves was mostly consumed. Calcia-rich phases are formed when the sonochemical stage is applied, and the lines characteristic of initial raw materials appear with relatively low intensities. In contrast, the samples not exposed to ultrasonic waves show the highest intensity in $\mathrm{CaO}$ lines. Therefore, it can be concluded that the application of ultrasound was clearly necessary to enhance the efficiency of the desired reaction.

It should be noted that in the system under study, the ultrasound caused significant quantities of the $\mathrm{C}_{12} \mathrm{~A}_{7}$ phase to appear after heat treatment, even in the mixture richer in $\mathrm{Al}_{2} \mathrm{O}_{3}$, with a proportion of $1: 2$ of $\mathrm{CaO}: \mathrm{Al}_{2} \mathrm{O}_{3}$. This indicates that in one hour of heat treatment at $1000^{\circ} \mathrm{C}$ the formation of $\mathrm{C}_{12} \mathrm{~A}_{7}$ is more favored than that of $\mathrm{CA}$ and $\mathrm{CA}_{2}$. This fact can be explained by the action of the ultrasound and the presence of water. The literature also reports that the formation of the $\mathrm{C}_{12} \mathrm{~A}_{7}$ phase is favored in this condition ${ }^{1}$. As Figure 1 shows, after the sonochemical process, there is a formation of tricalcium aluminate hydrate, $\mathrm{C}_{3} \mathrm{AH}_{6}$. Mineralogical changes occur in the heat treatment stage due to the process of dehydration, and $\mathrm{C}_{12} \mathrm{~A}_{7}$ is the first phase to be formed from that hydrate. With the increase in temperature and/or reaction time, this phase richer in $\mathrm{CaO}$ tends to convert into the other phases of the calcia-alumina system, depending on the availability and reactivity of alumina ${ }^{8,14}$.

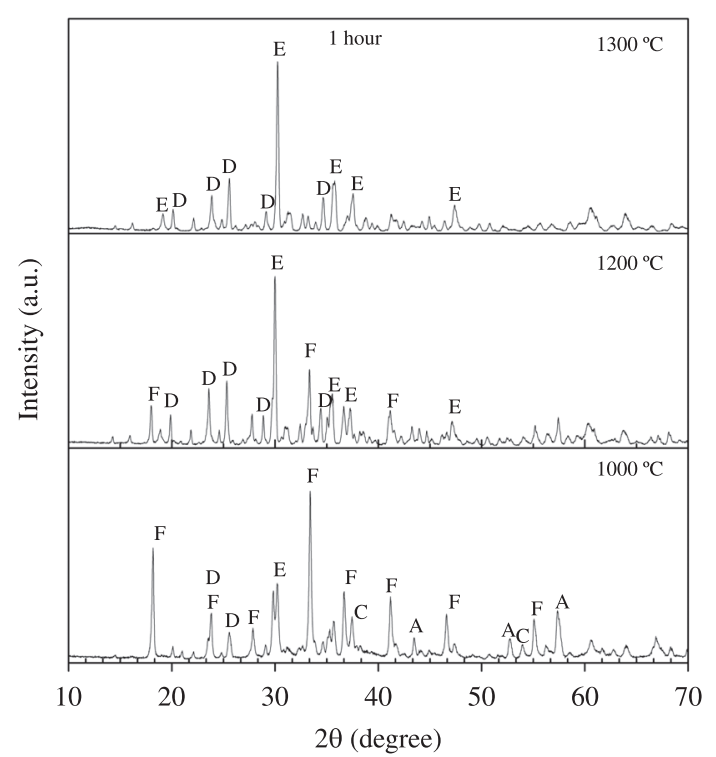

(a)
Considering that ultrasonic waves increase the efficiency of the reaction between calcia and alumina, a study was made of the effect of heat treatment temperature and time on the formation of phases.

Figure 5 presents diffraction patterns of samples with a molar proportion of 1:1 calcia:alumina obtained at different temperatures of heat treatment of 1 hour, Figure 5a, and 6 hours, Figure 5b. These patterns show the evolution of the phases in response to the different heat treatment conditions. The sample treated at $1000{ }^{\circ} \mathrm{C}$ predominantly consists of the $\mathrm{C}_{12} \mathrm{~A}_{7}$ phase, but also shows peaks characteristic of the $\mathrm{CA}$ and $\mathrm{CA}_{2}$ phases in smaller proportions and low peaks of alumina and calcia. At this temperature, the increase of 6 hours in the treatment time did not significantly affect the formation of phases. However, after the temperature was increased, it can be observed that the intensities of the lines of the $\mathrm{C}_{12} \mathrm{~A}_{7}$ phase declined considerably while those of CA, the target phase, were enhanced. The characteristic lines of the $\mathrm{CA}_{2}$ phase also appeared at $1200{ }^{\circ} \mathrm{C}$. At $1300{ }^{\circ} \mathrm{C}$, the $\mathrm{C}_{12} \mathrm{~A}_{7}$ phase was completely converted into $\mathrm{CA}$ and $\mathrm{CA}_{2}$ phases (within the limits of sensitivity of the diffractometer), with a predominance of CA. Once more, increasing the heat treatment time from 1 to 6 hours did not produce a significant effect, indicating that just one 1 hour of heat treatment would suffice to trigger the reactions. However, it was found that, at $1200{ }^{\circ} \mathrm{C}$, the conversion of $\mathrm{C}_{12} \mathrm{~A}_{7}$ into other phases was more effective in six hours of treatment than in only one hour.

Figure 6 depicts the diffraction patterns of samples with a molar proportion of 1:2 calcia:alumina heat-treated at 1000,1200 and $1300{ }^{\circ} \mathrm{C}$ for 1 hour, Figure $6 \mathrm{a}$, and for 6 hours, Figure $6 \mathrm{~b}$. The main crystalline phases of cement in the composition heat-treated at $1000{ }^{\circ} \mathrm{C}$ were $\mathrm{CA}, \mathrm{CA}_{2}$ and $\mathrm{C}_{12} \mathrm{~A}_{7}$, together with $\mathrm{Al}_{2} \mathrm{O}_{3}$ and $\mathrm{CaO}$. Upon increasing the temperature to $1200{ }^{\circ} \mathrm{C}$ and to $1300{ }^{\circ} \mathrm{C}$, the intensity of the peaks of the target phase, $\mathrm{CA}_{2}$, increased significantly,

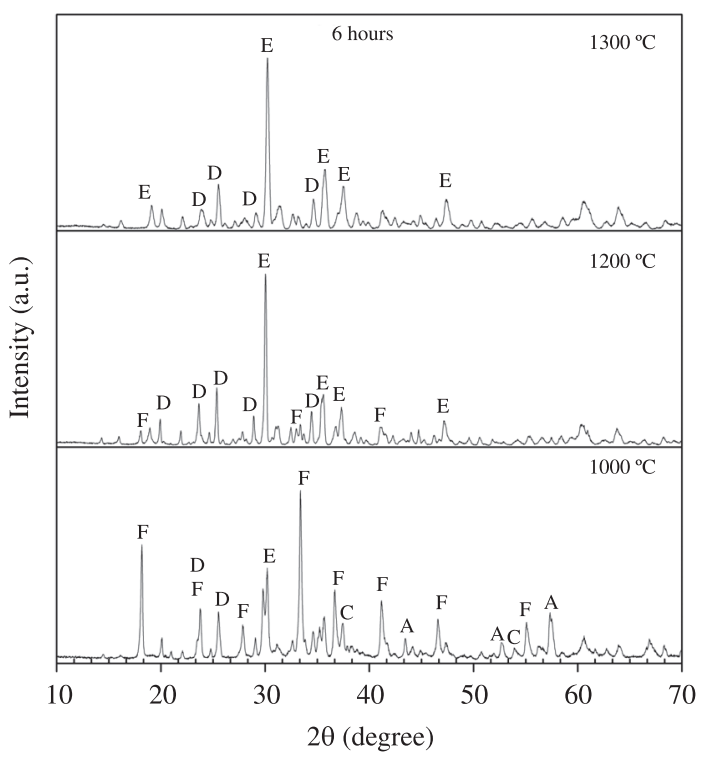

(b)

Figure 5. XRD-patterns of the samples with initial molar composition of 1:1 calcia:alumina subjected to ultrasound and heat-treated at three different temperatures for 1 hour (a), and 6 hours (b). Symbols: $\mathrm{A}-\mathrm{Al}_{2} \mathrm{O}_{3} ; \mathrm{C}-\mathrm{CaO} ; \mathrm{D}-\mathrm{CA}_{2} ; \mathrm{E}-\mathrm{CA} ; \mathrm{F}-\mathrm{C}_{12} \mathrm{~A}_{7}$. 


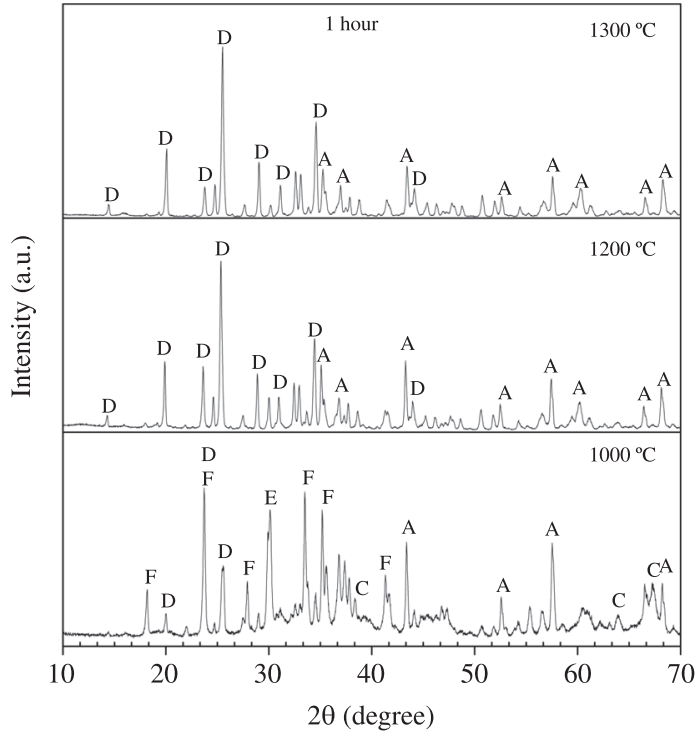

(a)

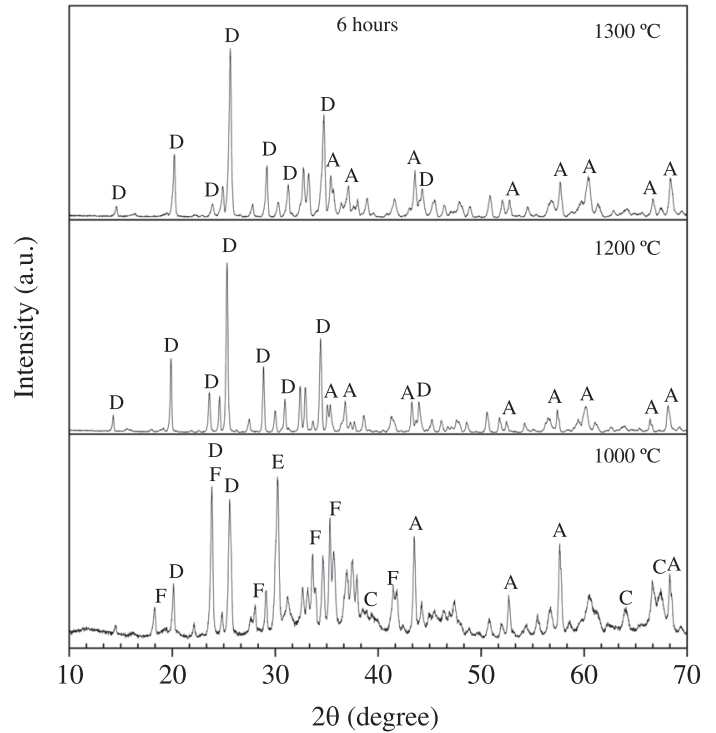

(b)

Figure 6. XRD patterns of the samples with initial molar composition of 1:2 calcia:alumina subjected to ultrasound and heat-treated at three different temperatures for 1 hour (a), and 6 hours (b). Symbols: $\mathrm{A}-\mathrm{Al}_{2} \mathrm{O}_{3} ; \mathrm{C}-\mathrm{CaO} ; \mathrm{D}-\mathrm{CA}_{2} ; \mathrm{E}-\mathrm{CA} ; \mathrm{F}-\mathrm{C}_{12} \mathrm{~A}_{7}$.

while the peaks of the $\mathrm{C}_{12} \mathrm{~A}_{7}$ phase disappeared (within the limits of sensitivity of the diffractometer). These samples also showed characteristic lines of alumina. It was found that, at the same temperature, increasing the heat treatment from 1 to 6 hours did not cause significant changes in the proportion among the phases in the final material, but the diffraction peaks of alumina were relatively lower than those of $\mathrm{CA}_{2}$ in 6 hours of firing at $1200^{\circ} \mathrm{C}$. Compared to Figure 5 , Figure 6 shows that the initial relative concentration of $\mathrm{C}_{12} \mathrm{~A}_{7}$ at the temperature of $1000{ }^{\circ} \mathrm{C}$ was lower in the $\mathrm{CA}_{2}$ material than in the CA material, since the composition of the former is further away from the equilibrium of the $\mathrm{C}_{12} \mathrm{~A}_{7}$ phase.

The diffraction patterns in Figures 5 and 6 reveal the complexity of the process of phase development in these materials. At $1000{ }^{\circ} \mathrm{C}$, several phases of the calcia-alumina system are formed, and a temperature increase of only $200{ }^{\circ} \mathrm{C}$ already favors the formation of the target phase.

The X-ray diffraction analysis of some materials did not indicate significant differences in terms of proportions of the phases. Therefore, the cements were analyzed semiquantitatively, using the Rietveld method to help interpret the results. This analysis involved only the $\mathrm{CA}_{2}$-cements. The results of this analysis are shown in Table 2 . Although the $\mathrm{X}$-ray diffraction patterns of these samples (Figure 6) also revealed other phases, only the dominant phases, $\mathrm{CA}_{2}$ (D) and $\mathrm{Al}_{2} \mathrm{O}_{3}$ (A) were analyzed semi- quantitatively.

From Table 2, it can be observed that the increase in firing temperature favors the increase in the content of $\mathrm{CA}_{2}$ while the $\mathrm{Al}_{2} \mathrm{O}_{3}$ is consumed. This result is consistent with the literature, which foresees the formation of the $\mathrm{CA}_{2}$ phase and the consumption of alumina with an increasing temperature and/or time of heat treatment ${ }^{1}$.

Figure 7 depicts the particle morphology of the samples of the CA and $\mathrm{CA}_{2}$ compositions heat-treated at 1000, 1200 and $1300{ }^{\circ} \mathrm{C}$ for one hour. It should be noted in the SEMmicrographs that, after the heat treatment, the morphology of the particles changed from that of the samples prior to

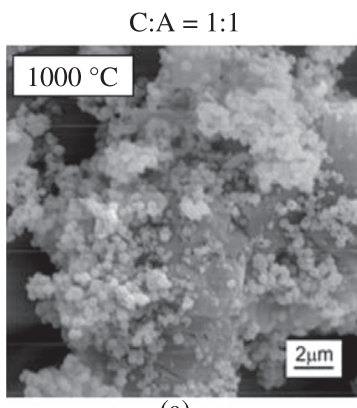

(a)

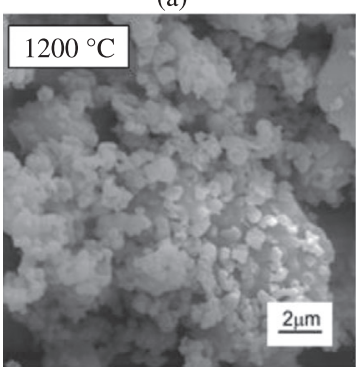

(c)

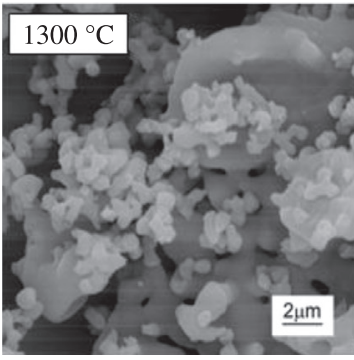

(e)

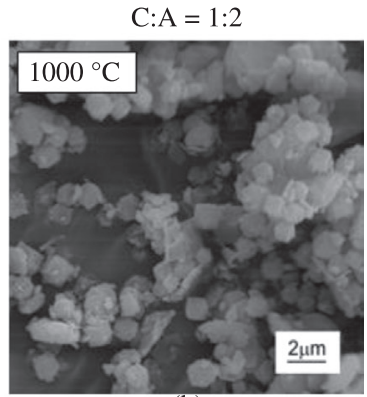

(b)

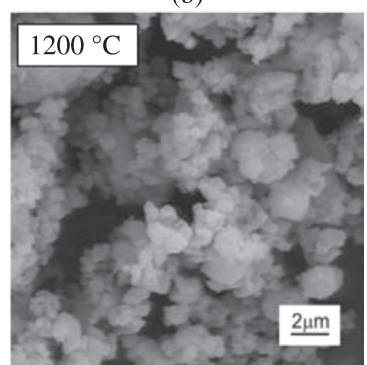

(d)

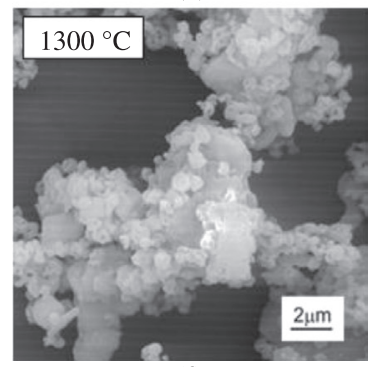

(f)

Figure 7. SEM micrographs of the samples with initial molar compositions of 1:1 calcia:alumina: (a), (c) and (e), and of 1:2, (b), (d) and (f), all heat-treated for 1 hour at temperatures indicated in the pictures. 
Table 2. Concentrations of $\mathrm{CA}_{2}$ and $\mathrm{Al}_{2} \mathrm{O}_{3}$ phases for materials initially concentrated on $\mathrm{CA}_{2}$ composition obtained using the Rietveld method.

\begin{tabular}{cccc}
\hline \multicolumn{2}{c}{$\mathbf{C A}_{2}$-Cement } & \multicolumn{2}{c}{ Concentration (wt. (\%)) } \\
\hline $\begin{array}{c}\text { Temperature } \\
\left({ }^{\circ} \mathbf{C}\right)\end{array}$ & $\begin{array}{c}\text { Time } \\
(\text { hours) }\end{array}$ & $\begin{array}{c}\text { Phase } \mathbf{C A}_{2} \\
\left(\mathbf{C a A l}_{4} \mathbf{O}_{7}\right)\end{array}$ & Phase A $\left(\mathbf{A l}_{2} \mathbf{O}_{3}\right)$ \\
\hline 1000 & 6 & 23.2 & 26.71 \\
1200 & 6 & 84.5 & 11.87 \\
1300 & 1 & 86.27 & 7.08 \\
& 6 & 90 & 6.12 \\
\hline
\end{tabular}

heat treatment, Figure 2. These morphological changes are the result of the formation of the various phases of calcium aluminate that occur as a function of temperature. The micrographs depict the different particle sizes, indicating that some are large and have irregular shapes, while a finer particulate, on the nanometric scale, appears in regions of agglomeration. Figures $7 \mathrm{e}$ and $7 \mathrm{f}$, which depict materials heat-treated at $1300{ }^{\circ} \mathrm{C}$, show a necking formation similar to what occurs at the beginning of sintering, suggesting particle coalescence. This process occurred in both the CA and $\mathrm{CA}_{2}$ compositions, but this effect was more visible in the CA sample. It should be kept in mind that the melting point of CA is $1605^{\circ} \mathrm{C}$, while that of $\mathrm{CA}_{2}$ is $1750{ }^{\circ} \mathrm{C}$, so there is a greater tendency for sintering among the particles of $\mathrm{CA}$ than of $\mathrm{CA}_{2}$. This sample (CA) contains larger particles with morphology similar to that of some particles in the sample of the same composition treated at $1000{ }^{\circ} \mathrm{C}$ (Figure 7a).

\subsection{Mechanical strength}

An evaluation was also made of the mechanical strength of these materials, based on the splitting tensile test. The hydraulic phases formed when aluminous cements are mixed with water are responsible for the development of the mechanical strength of green material. The type and proportions of the different hydrates that can be formed during the hydration process are strongly dependent on the mineralogical composition of the cement, the water/cement ratio, and particularly on the curing temperature ${ }^{15}$. Because these last two variables were controlled during the experiment, the differences in the values of mechanical strength may be attributed mainly to the diversified proportion among the phases that the materials prepared using the sonochemical process presented after the different heat treatments.

Figure 8 compares the mechanical strength of the pastes containing $50 \%$ of alumina (A1000 SG) and 50\% of the cement synthesized in the various conditions of heat treatment. The mechanical strength of the materials prepared by the sonochemical process was compared to that of a material prepared with the commercial calcium aluminate cement, Secar 71. After drying, the material prepared with Secar 71 showed a splitting tensile strength of $1.75 \mathrm{MPa}$. The test specimens showed a gradual increase in mechanical strength with an increasing temperature and duration of heat treatment applied to the synthesis of the calcium aluminates. The low mechanical strength of materials 1, 2, 3 and 4 (see horizontal axis in Figure 8), in the case of the CA-cement, may be related to the presence of the $\mathrm{C}_{12} \mathrm{~A}_{7}$ phase. This

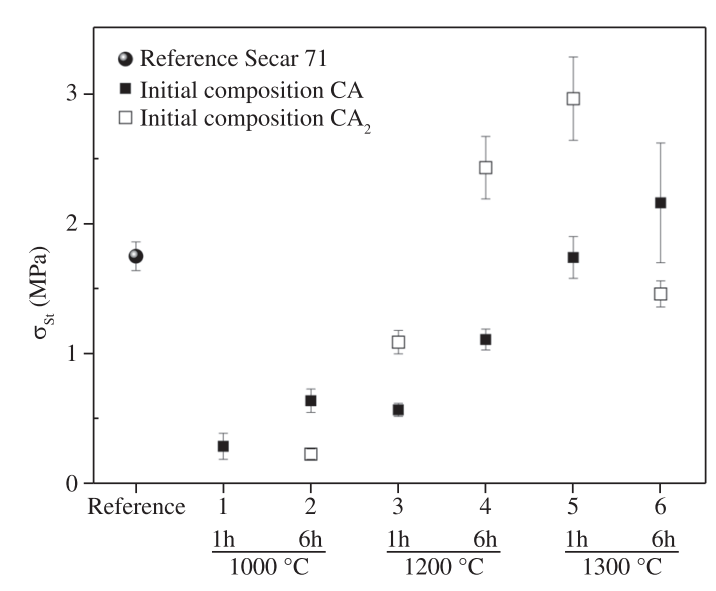

Figure 8. Splitting tensile strength, $\sigma_{\text {st }}$, of cement and alumina pastes, using the calcium aluminate cements prepared by the sonochemical process under different heat treatment conditions, and a commercial calcium aluminate cement as reference.

phase hydrates and hardens rapidly, hindering the hydration of the other phases, which implies low mechanical strength of the test specimens. The test specimens prepared with the $\mathrm{CA}_{2}$-materials showed higher mechanical strength than those prepared with the CA-materials, starting from the heat treatment at $1200{ }^{\circ} \mathrm{C}$ for 1 hour, except for the sample heat-treated at $1300{ }^{\circ} \mathrm{C}$ for 6 hours $(1.46 \mathrm{MPa})$. The mechanical strength of the test specimens prepared with the $\mathrm{CA}_{2}$-material and heat-treated at $1000{ }^{\circ} \mathrm{C}$ for 1 hour could not be measured, because after drying there was significant retraction of the bodies, causing them to lose their cylindrical shape. This retraction may be associated with the phase conversions that occur in hydrates during curing. The test specimens made of CA-materials 5 and 6 presented a high strength, whose values were similar to those of the material prepared using Secar 71, which was taken as a reference. Among all the materials, materials 4 and 5 prepared with the $\mathrm{CA}_{2}$-cement showed the highest values of mechanical strength, which were even higher than that of the material prepared with the cement of reference.

Based on the results of the semi-quantitative analyses (Table 2) and mechanical strength (Figure 8), it can be observed that the increase in strength $\left(\sigma_{\mathrm{st}}\right)$ was accompanied by an increase in the content of the $\mathrm{CA}_{2}$ phase and a reduction in the content of $\mathrm{Al}_{2} \mathrm{O}_{3}$. Initially, one could attribute the improved mechanical strength of these materials to the increase in $\mathrm{CA}_{2}$ concentration. However, some aspects should be considered. There was an increase in strength which was disproportional to the increase in the concentration of $\mathrm{CA}_{2}$ phase, and the material treated at $1300{ }^{\circ} \mathrm{C}$ for 6 hours showed a different behavior. Therefore, one can consider that the development of mechanical strength is not only associated with the contents of the phases present in these materials. These differences may also be influenced by the particle size distribution of the material obtained at the end of the process and by the presence, in low concentrations, of phases with high hydraulicity, which were not detected by X-ray diffraction. 
Figure 9 shows the XRD-patterns of materials 1, 3 and 5 (see the horizontal axis in Figure 8) prepared with cements in the initial molar proportion of 1:1 calcia:alumina. For purposes of reference, the diffractogram of the paste prepared with Secar 71 cement is also shown.

As can be seen in all the diffractograms, the main products of hydration were $\mathrm{C}_{3} \mathrm{AH}_{6}$ and $\mathrm{AH}_{3}$, which are hydrates typically formed when curing at temperatures above $35{ }^{\circ} \mathrm{C}^{3,5}$. Alumina with a crystalline corundum structure $\left(\alpha-\mathrm{Al}_{2} \mathrm{O}_{3}\right)$ was detected in the diffractogram of all the samples analyzed as principal lines, since it was added to the composition of the paste (50 wt. (\%)) as a base and in order to approximate the hydration environment that occurs in an alumina-based refractory concrete.

Figure 10 shows the diffractograms of materials 2, 4 and 6 (see horizontal axis in Figure 8) prepared with cements in the initial molar proportion of 1:2 calcia:alumina.

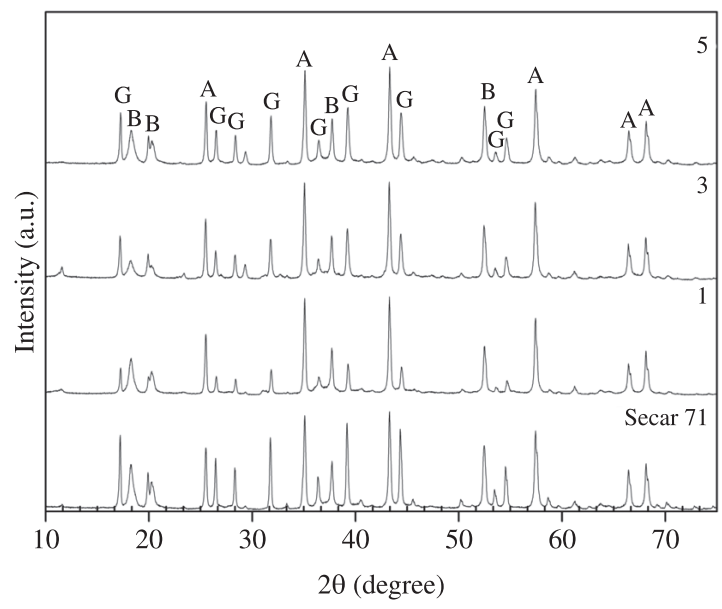

Figure 9. XRD-patterns of the cement and alumina pastes cured at $50{ }^{\circ} \mathrm{C}$. Materials 1, 3 and 5 (horizontal axis of Figure 8) were prepared with cements having an initial molar composition of 1:1 calcia:alumina. Symbols: $\mathrm{A}-\mathrm{Al}_{2} \mathrm{O}_{3} ; \mathrm{B}-\mathrm{Al}(\mathrm{OH})_{3} ; \mathrm{G}-\mathrm{C}_{3} \mathrm{AH}_{6}$.

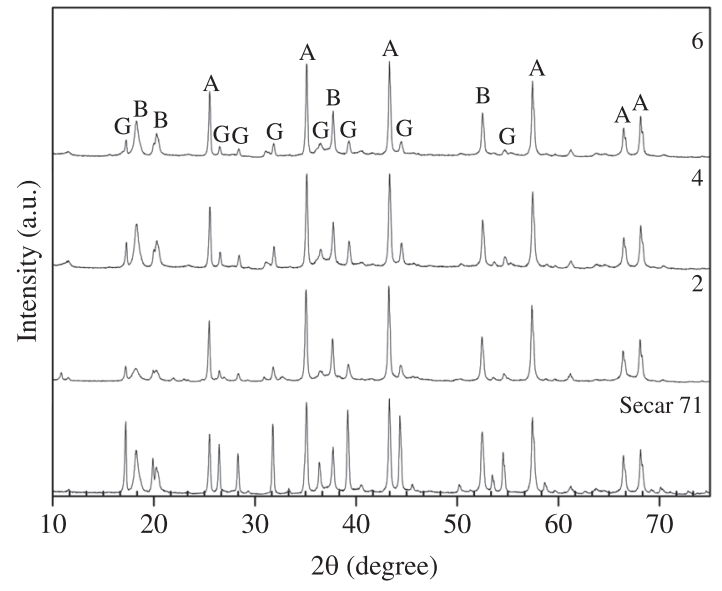

Figure 10. XRD-patterns of cement and alumina pastes cured at $50{ }^{\circ} \mathrm{C}$. Materials 2, 4 and 6 (horizontal axis in Figure 8) were prepared using cement with an initial molar composition of 1:2 calcia:alumina. Symbols: $\mathrm{A}-\mathrm{Al}_{2} \mathrm{O}_{3} ; \mathrm{B}-\mathrm{Al}(\mathrm{OH})_{3} ; \mathrm{G}-\mathrm{C}_{3} \mathrm{AH}_{6}$.
A comparison of the diffractograms in Figures 9 and 10 reveals that the hydration products are the same in both initial cement compositions, $\mathrm{CA}$ and $\mathrm{CA}_{2}$. However, note that the hydrates formed in the materials prepared with the synthesized CA-cements (Figure 9), contain relative quantities very similar to the products formed in the material prepared with Secar 71 cement. Once more, it is interesting to note, especially by analysing the diffractograms of the synthesis products, that their final composition depends on the molar ration of the raw materials and on the heat treatment conditions applied to the preparation of the cements. Note that in the case of the CA-cement composition, depending on the firing conditions, the synthesis product has a proportion among the phases, which is very similar to that of the commercial cement. Moreover, pastes made of CA-cements and alumina showed mechanical strength close to that of the paste made of Secar 71 (see Figure 8, $1300{ }^{\circ} \mathrm{C}, 1$ and 6 hours). Remembering that the most important constituents of Secar 71, in decreasing order of concentration, are CA (61 wt. (\%)), and $\mathrm{CA}_{2}$ (37.5 wt. (\%)).

From the SEM images of the samples, it was not possible to find a correlation between the morphological changes that could clarify the samples' mechanical behavior.

Moreover, the results presented here also did not explain the low mechanical strength of the material made of the $\mathrm{CA}_{2}$-cement and heat-treated at $1300{ }^{\circ} \mathrm{C}$ for 6 hours (point 6 in Figure 8). The entire processing of cement and test specimen preparation was repeated, but the results showed no significant variation, reproducing the ones in Figure 8.

We are engaged in ongoing studies to quantify the phases present in the synthesized cements, seeking to clarify the mechanical behavior of the refractory materials obtained. Nevertheless, this work demonstrates how promising the sonochemical route developed here is in obtaining materials of significant importance for refractory castables.

\section{Conclusions}

The sonochemical process effectively enhanced the reactivity of the raw materials, particularly those of calcia for both formulations used in this work, i.e. CA and $\mathrm{CA}_{2}$.

It was found that treatment temperature is much more significant than treatment time insofar as the development of aluminous phases is concerned. In the case of the CAmaterial, at $1200{ }^{\circ} \mathrm{C}$ the synthesis product already has a proportion of phases similar to that of the refractory calcium aluminate cement used as a reference. That temperature is at least $200{ }^{\circ} \mathrm{C}$ lower than that required in the conventional manufacturing process.

The test specimens prepared using the materials synthesized by the sonochemical process in which the target phases began to prevail, materials 5 and 6 in the case of the CA-cement and materials 4, 5 and 6 in that of the $\mathrm{CA}_{2}$-cement, presented good mechanical strength. Although the material's phase composition is an important factor influencing the development of the mechanical strength of test specimens, there should be differences that are not detected by X-ray diffraction.

The results obtained in this work, albeit still only partial, demonstrate that the sonochemical process has a strong potential for obtaining calcium aluminates at lower temperatures than those used by conventional routes. 


\section{Acknowledgements}

The authors would like to acknowledge CNPq (Brazil) for a Master's scholarship (process \# 143525/2008-5), for research productivity grants (process \# 304980/2003-0 and 301073/2006-6) and for an undergraduate scholarship

\section{References}

1. Kopanda JE and MacZura G. Production processes, properties, and aplication for calcium aluminate cements. In: Hart LD. Alumina Chemicals. Westerville Science and Technology Handbook; 1990. p. 171-184.

2. Cüneyt TA. Chemical preparation of the binary compounds in the calcia-alumina system by self-propagating combustion synthesis. Journal America Ceramic Society. 1998; 81(11):2853-63.

3. Parr C, Roesky R and Wohrmeyer C. Calcium aluminate cements for unshaped refractories, review papers. $C N$ Refractories. 2001; 5:6-12.

4. Lee WE, Vieira W, Zhang S, Ahari KG, Sarpoolaky H and Parr C. Castable refractory concretes. International Materials Reviews. 2001; 46(3):145-167. http://dx.doi. org/10.1179/095066001101528439

5. Lea FM. The Chemistry of Cement and Concrete. 3rd ed. London: Edward Arnold Publishers; 1970. p. 28-81; $177-$ 249; 490-527.

6. Pena $\mathrm{P}$ and Aza AH. Cementos de aluminatos cálcicos. constituición, características y aplicaciones. In: Baudín C, editor. Refractarios Monolíticos. Madrid: Sociedad Española de Cerámica y Vidrio; 1999. p. 85-106.

7. Parker KM and Sharp JH. Refractory calcium aluminate cements. Transactions and Journal of the British Ceramic Society. 1982; 81:35-42. (process \# 501555-63). We are also indebted to Alcoa Aluminum S.A. for donating the A50-alumina raw material. We are also grateful to the Materials Engineering undergraduate student, Caio Cesar Dente Exposito, for the help in the mechanical tests.

8. Gülgün MA, Popoola OO and Kriven WM. Chemical synthesis and characterization of calcium aluminate powders. Journal of the American Ceramic Society. 1994; 77(2):531-39. http:// dx.doi.org/10.1111/j.1151-2916.1994.tb07026.x

9. Singh VK, Ali MM and Mandal UK. Formation Kinetics of Calcium Aluminates. Journal of the American Ceramic Society. 1990; 73(11):872-76. http://dx.doi. org/10.1111/j.1151-2916.1990.tb05128.x

10. Martines MAU, Davolos MR and Jafelicci Júnior M. O efeito do ultra-som em reações químicas. Química Nova. 2000; 23(2):251-156. http://dx.doi.org/10.1590/S010040422000000200017

11. Gedanken A. Using sonochemistry for the fabrication of nanomaterials. Ultrasonics Sonochemistry. 2004; 11:4755. PMid:15030779. http://dx.doi.org/10.1016/j. ultsonch.2004.01.037

12. Rodrigues FA. Low-temperature synthesis of cements from rice hull ash. Cement and Concrete Research. 2003; 33(10):15251529. http://dx.doi.org/10.1016/S0008-8846(03)00104-2

13. Wefers K and Misra C. Oxides and hydroxides of aluminium. Alcoa Laboratories; 1987. p. 46-55.

14. Nishikawa A. Technology of monolithic refractories. Tokyo: Plibrico Japan Co, Ltd.; 1984. p. 83-170.

15. Garcia JR, Oliveira IR and Pandolfelli VC. Processo de Hidratação e os Mecanismos e Atuação dos Aditivos Aceleradores e Retardadores de Pega do Cimento de Aluminato de Cálcio. Revista Cerâmica. 2007; 53:42-56. 